\title{
OPEN Publisher Correction: Genomic analysis of the emergence of drug- resistant strains of Mycobacterium tuberculosis in the Middle East
}

\section{Essam J. Alyamani, Sarah A. Marcus $\mathbb{D}^{0}$, Sarah M. Ramirez-Busby, Chungyi Hansen, Julien Rashid, Amani El-kholy, Daniel Spalink, Faramarz Valafar, Hussein A. Almehdar, Asif A. Jiman-Fatani, Mohamed A. Khiyami \& Adel M. Talaat}

Correction to: Scientific Reports https://doi.org/10.1038/s41598-019-41162-9, published online 14 March 2019

In the original version of this Article, there were errors in Affiliations of authors Hussein A. Almehdar and Asif A. Jiman-Fatani which were incorrectly listed as 'Department of Microbiology and Medical Parasitology, Faculty of Medicine, King Abdulaziz University, Jeddah, Saudi Arabia' and 'Department of Biology, Faculty of Science, King Abdulaziz University, Jeddah, Saudi Arabia’ respectively.

The correct affiliations are listed below.

Affiliation of Hussein A. Almehdar:

Department of Biology, Faculty of Science, King Abdulaziz University, Jeddah, Saudi Arabia.

Affiliation of Asif A. Jiman-Fatani:

Department of Medical Microbiology and Parasitology, Faculty of Medicine, King Abdulaziz University, Jeddah, Saudi Arabia.

These errors have now been corrected in the PDF and HTML versions of the Article.

In the original version of this Article, the author Asif A. Jiman-Fatani was incorrectly indexed. This error has now been corrected.

(c) Open Access This article is licensed under a Creative Commons Attribution 4.0 International License, which permits use, sharing, adaptation, distribution and reproduction in any medium or format, as long as you give appropriate credit to the original author(s) and the source, provide a link to the Creative Commons license, and indicate if changes were made. The images or other third party material in this article are included in the article's Creative Commons license, unless indicated otherwise in a credit line to the material. If material is not included in the article's Creative Commons license and your intended use is not permitted by statutory regulation or exceeds the permitted use, you will need to obtain permission directly from the copyright holder. To view a copy of this license, visit http://creativecommons.org/licenses/by/4.0/.

(C) The Author(s) 2019 